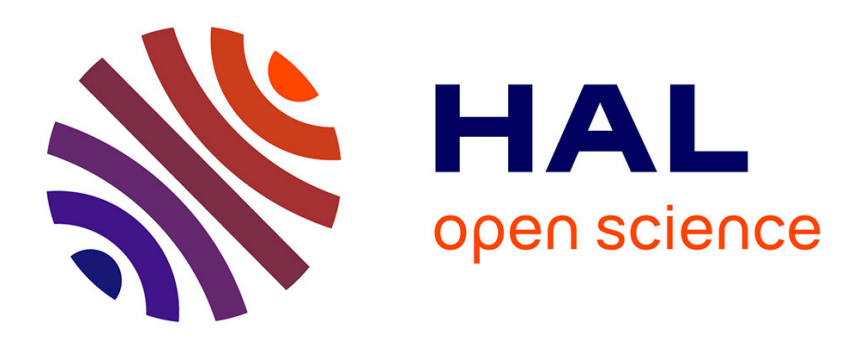

\title{
Spatial dissimilarities in seasonal cycle of PM10 particulate matters in Seoul, Korea \\ Parth Bansal
}

\section{To cite this version:}

Parth Bansal. Spatial dissimilarities in seasonal cycle of PM10 particulate matters in Seoul, Korea. 2019. hal-02193095

\author{
HAL Id: hal-02193095 \\ https://hal.science/hal-02193095
}

Preprint submitted on 24 Jul 2019

HAL is a multi-disciplinary open access archive for the deposit and dissemination of scientific research documents, whether they are published or not. The documents may come from teaching and research institutions in France or abroad, or from public or private research centers.
L'archive ouverte pluridisciplinaire HAL, est destinée au dépôt et à la diffusion de documents scientifiques de niveau recherche, publiés ou non, émanant des établissements d'enseignement et de recherche français ou étrangers, des laboratoires publics ou privés. 


\title{
Spatial dissimilarities in seasonal cycle of PM10 particulate matters in Seoul, Korea
}

\author{
Parth Bansal \\ Graduate School of Environmental Studies, Seoul National University
}

\begin{abstract}
The increase in spatial and temporal resolution of pollution data has advanced the understanding of trend in pollutant concentration through time and space. However, this has also made inspection of time series and the relation between observations from different monitoring stations difficult to comprehend. In this study, we decompose $\mathrm{PM}_{10}$ concentration time series $(2010$ - 2018) from 40 Air Quality Monitoring Stations (AQMs) in Seoul and then cluster the seasonal cyclic components using K-Means and K-Shape algorithms. Firstly, the influence of diurnal, weekly and annual cycle on $\mathrm{PM}_{10}$ concentration is shown. Secondly, the clustering results illustrate that both algorithms are useful in determining AQMs with similar cycles, and together provide a comprehensive understanding of spatial differences in pollutant concentration.
\end{abstract}

Keywords: Air Pollution; Seasonal Cycle; K-Shape; Seoul Korea

\section{Introduction}

Air pollution has been a cause of concern due to its impact on human health (Kampa and Castanas 2008) and weather and atmospheric conditions (Stern 1977). Among the major air pollutants, the second Seoul air quality improvement plan (ME 2013) identifies $\mathrm{PM}_{10}, \mathrm{NO}_{\mathrm{X}}$ and $\mathrm{SO}_{\mathrm{X}}$ as major contributors to air pollution. While both $\mathrm{PM}_{10}$ (particle diameter $<10 \mu \mathrm{m}$ ) and $\mathrm{PM}_{2.5}$ (particle diameter $<2.5 \mu \mathrm{m}$ ) are monitored, Air Quality Index (AQI) deterioration in Seoul is primarily due to high concentration of $\mathrm{PM}_{10}$ matter. Especially during the Asian dust season (Zhang, Gong et al. 2003), air quality frequently fall below unhealthy level on EPA scale.

(Li, Qian et al. 2014) have shown that significant variation exists in pollutant concentrations within a city boundary. However, most of the effort under the air quality improvement plan of Seoul and associated legislations have been spatially and temporally agnostic. Thus, in this study, hourly $\mathrm{PM}_{10}$ dataset from 40 air quality monitoring stations was analyzed for the period of 2010-18. Consequently, we aimed to investigate the effect of time (diurnal, weekly and annual cycle) on $\mathrm{PM}_{10}$ concentration and differences in each of three cycles from 40 AQMs. In doing so, we aim to highlight methods for time series analysis and clustering, which can simplify the analysis of air pollution data.

\section{Methods}

2.1 Study Area and AQMs

Seoul $\left(37^{\circ} 1^{\prime} \mathrm{N}, 126^{\circ} 58^{\prime} \mathrm{E}\right)$ is the largest city of South Korea and fall under humid continental climatic zone under KöppenGeiger classification. It has a total land area of $605 \mathrm{KM}^{2}$ with an average elevation of $38 \mathrm{M}$. It is polycentric with high and medium density residential area and about $25.29 \%$ of land falls under the regulated green belt where only limited

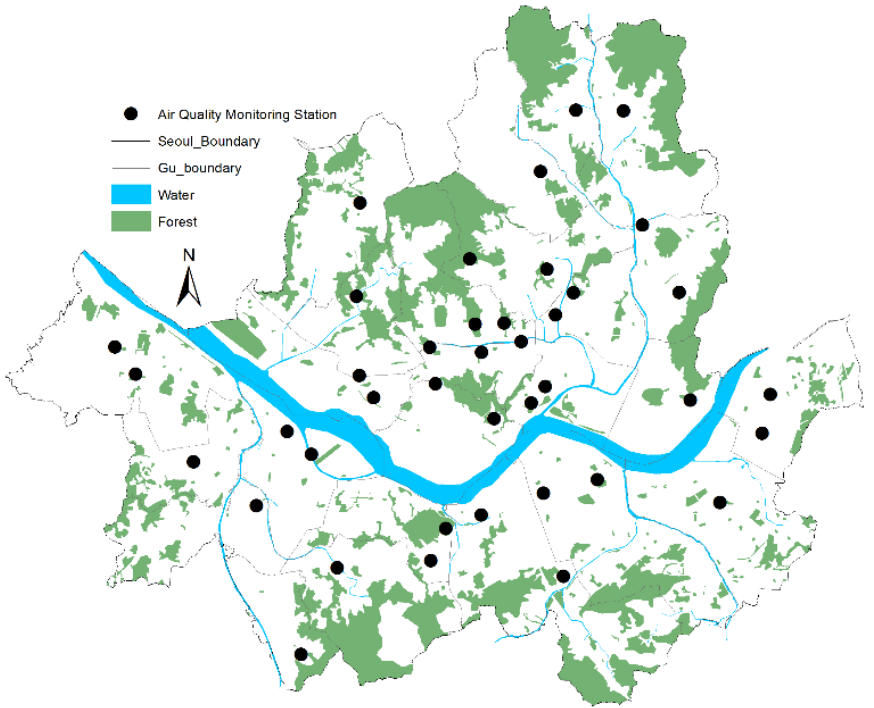

Figure 1 Location of AQMs in Seoul development is allowed. The area has 
four distinct seasons and due to a combination of local climate conditions, internal and foreign anthropogenic emissions and Asian dust, winter usually has poor air quality.

Air pollution is measured hourly as mean of readings at $5 \mathrm{~m}$ minute interval by 40 air quality monitoring stations (AQMs) within the boundary of Seoul, shown in figure 1. For PM10, ambient dust monitor using $\beta$-ray absorption method is used which has minimum detection limit of $<1 \mu \mathrm{m} / \mathrm{m}^{3}$ with the precision of $\pm 2 \mu \mathrm{m} / \mathrm{m}^{3}$ (Ahmed, Kim et al. 2015).

\subsection{Data Processing}

\subsubsection{Time Series Decomposition}

Additive decomposable time series model (Harvey and Peters 1990) is defined as:

$$
\mathrm{y}(\mathrm{t})=\mathrm{g}(\mathrm{t})+\mathrm{s}(\mathrm{t})+\mathrm{h}(\mathrm{t})+\varepsilon_{t}(1)
$$

Where $g(t)$ is long term trend (non-periodic changes), $s(t)$ is periodic changes and $h(t)$ is holiday effect, i.e. irregularly scheduled events. $\varepsilon_{t}$ is error term contain changes not accounted by the model. Alternatively, time series can also be decomposed multiplicatively, however, based on preliminary inspection using graphs and lower mean absolute percentage error (MAPE) (Armstrong and Collopy 1992) of both models, additive decomposition has been used in this study. For modelling $g(t)$ piecewise linear regression (McZgee and Carleton 1970) with time as regressor is used. Since pollution is also a function of anthropogenic activity which can have multi-period seasonality, Fourier series (Harvey and Shephard 1993) was used to model effect of diurnal, weekly and annual cycle $(s(t))$. Holidays $h(t)$ were not included in the model.

The implementation of model can be found in python library fbprophet (Taylor and Letham 2018).

\subsubsection{Time Series Clustering}

As the number of AQMs increases along with the temporal frequency of observations, huge amount of detailed air quality data is generated. Different techniques including time series clustering have been developed to identify similar observations and reduce costly human supervision, not only as detached analysis but also as a step for pre-processing.

We use time series clustering to identify similar cycles from 40 AQMs datasets. (Montero and Vilar 2014) described two broad categories for time series similarity (or dissimilarity) investigations: 1) Shape based, where the objective is to compare the geometric profile of the series. 2) Structure based, where the objective is to find the mutual dependency arrangement. In this research, since our objective is to investigate the similarity in $\mathrm{PM}_{10}$ profile across different AQMs, we use algorithms primarily meant for shape based investigations.

\subsubsection{Classification Algorithms}

K-Means, in general clustering, has been one of the most popular algorithm. To extend it into time series clustering, dissimilarity measures such as Euclidean distance and dynamic time warping (DTW) (Berndt and Clifford 1994) are used. On the other hand, K-Shape (Paparrizos and Gravano 2015) is a relatively new algorithm which uses normalized cross correlation to measure dissimilarity. Further, while K-Means uses an average sequence of all the sequences to derive centroid for clustering, KShape compute centroid by minimizing the sum of squared distance to all the sequences. In this study, we used both K-Means based on DTW and K-Shape clustering. The implementation of both algorithms can be found in python library tslearn (Tavenard 2017). The number of clusters while subjective to authors' investigation, were based on the results of Silhouette score (DTW and Euclidean distance as metric) (Rousseeuw 1987), Gap statistic (Tibshirani, Walther et al. 2001) and mean square error (MSE). 


\section{Results}

Hourly $\mathrm{PM}_{10}$ data between 2010 - 18, for AQMs located across Seoul was collected and cleaned. 37 of 40 AQMs were active throughout the study period. 2 AQMs started functioning from April 2011, while 1 AQM was retired at the end of 2014. Across all the AQMs, on average, out of 8760 hours in a non-leap year, 8692 observations were recorded. Overall, there are 3,074,436 observations in total across the whole dataset. Figure 1 shows $\mathrm{PM}_{10}$ concentration for individual AQMs as well as the arithmetic mean. As with any large dataset, it is difficult to derive any systematic conclusion from simple visualization, but generally, peaks are observed in winter (Nov - Feb) and troughs in summer (July-Sept).

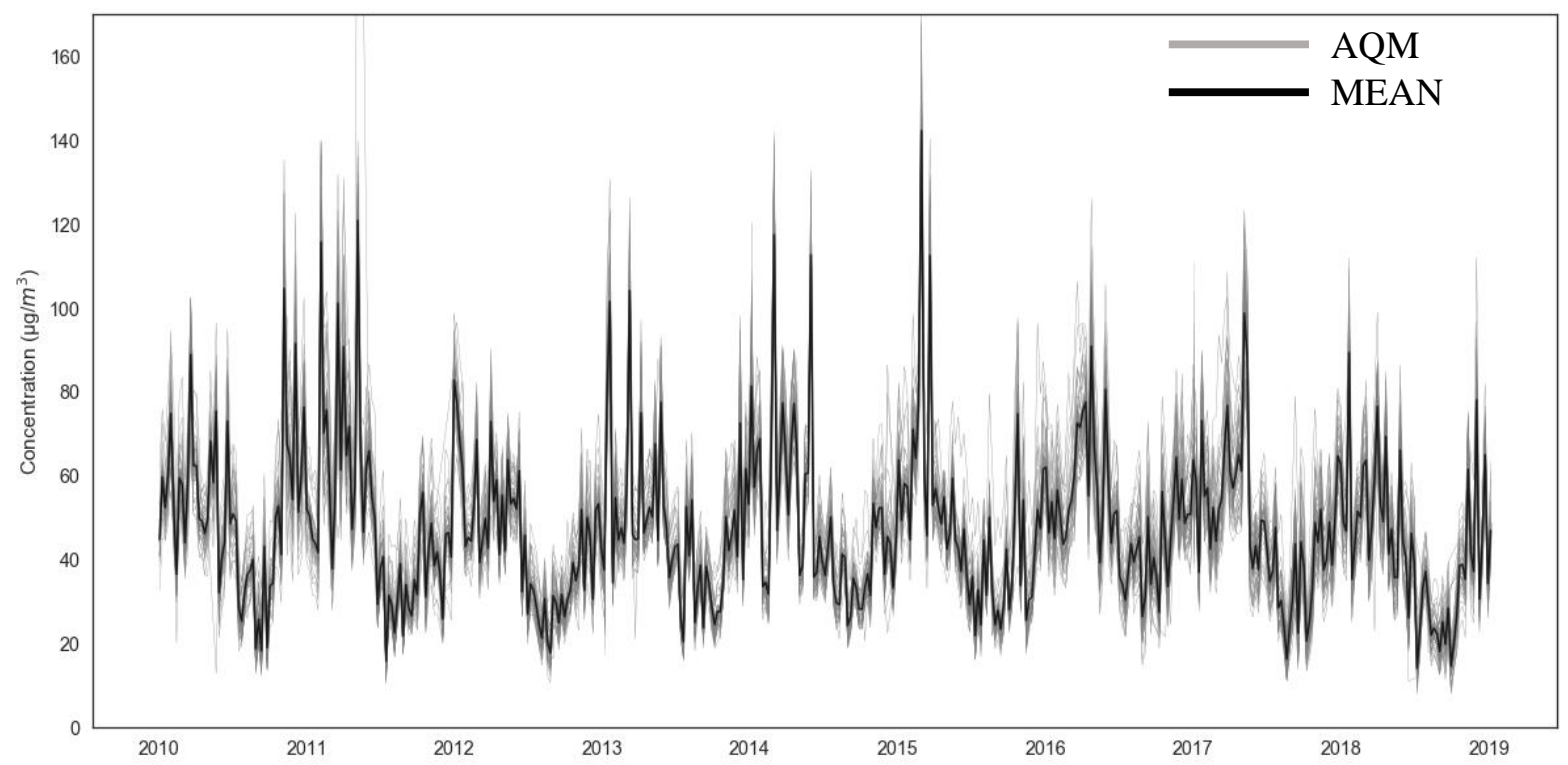

Figure 2 PM10 observations for 40 AQM between 2010 - 2018 and their mean.

As per discussion in section 2.2, time series for each AQM was additively decomposed. All three seasonal cyclic components were then clustered separately using K-Means (DTW) and K-Shape algorithm. Annual and weekly cycles were divided into 3 clusters while daily cycles have 4 clusters. The results of decomposition and the subsequent clustering is shown in Figure 2 to 4, along with the mean of each cluster.
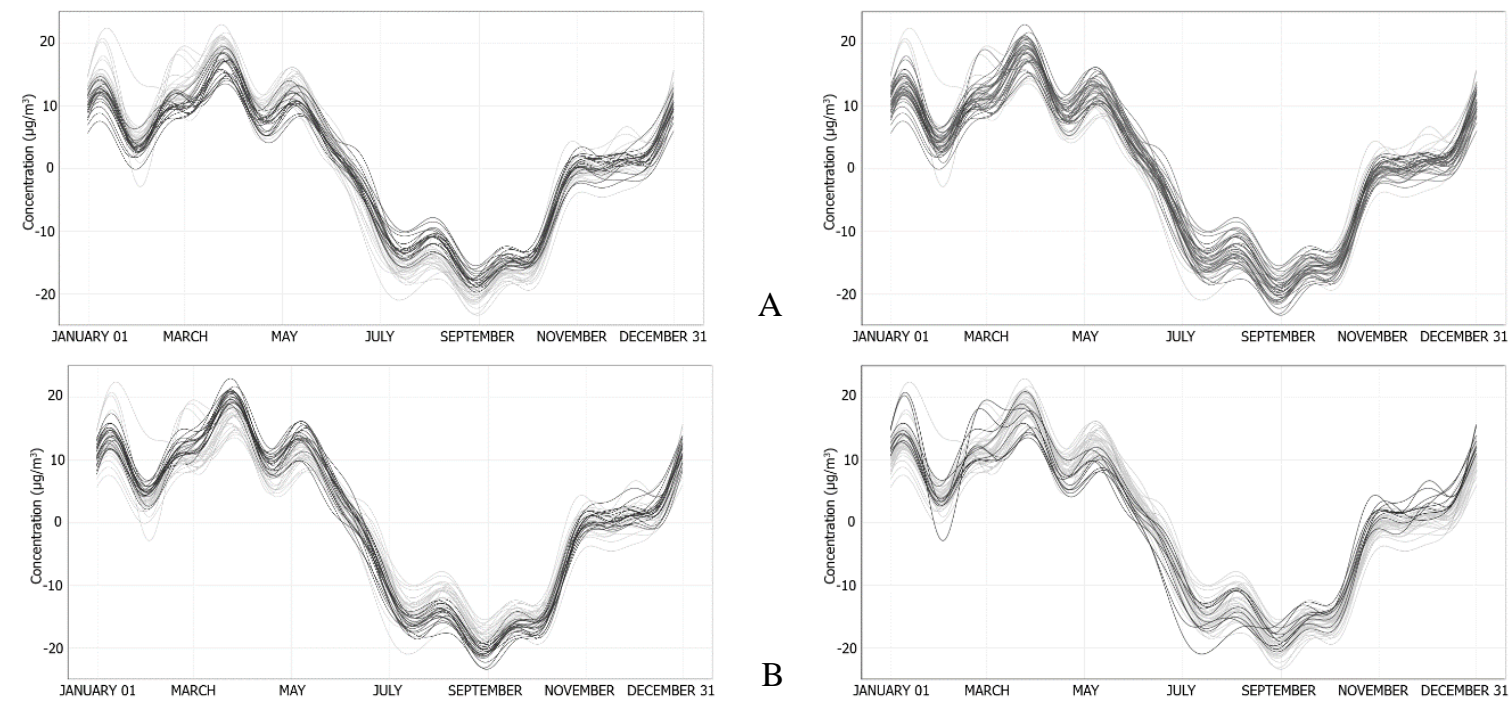

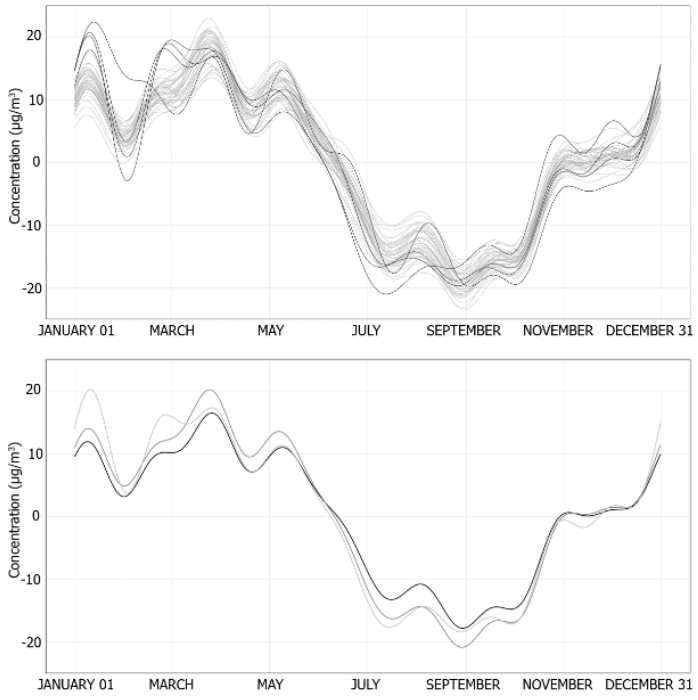

C

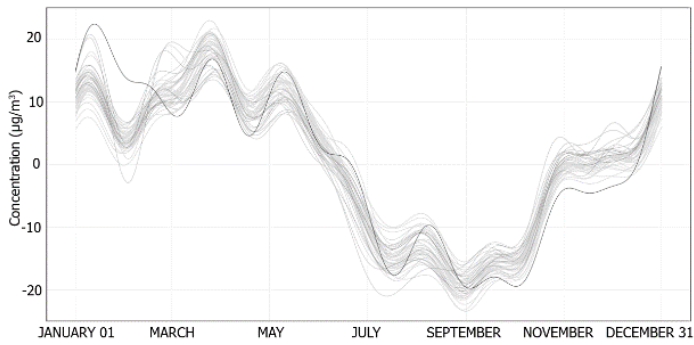

Mean

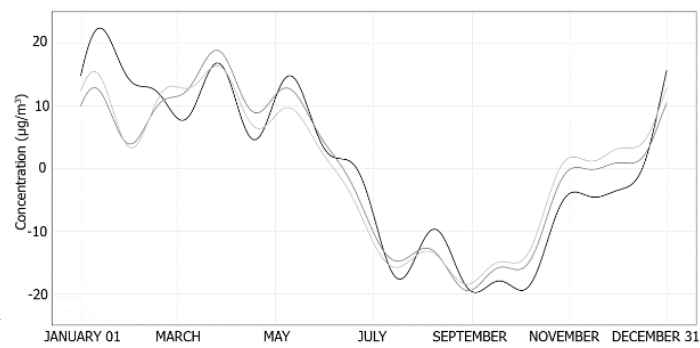

Figure 3 Annual seasonal component of PM10. Left A-C, clustering from K-Means (DTW), Left D, mean of KMeans (DTW) clusters. Right A-C clustering from $K$-Shape, Right D, mean of K-Shape cluster.
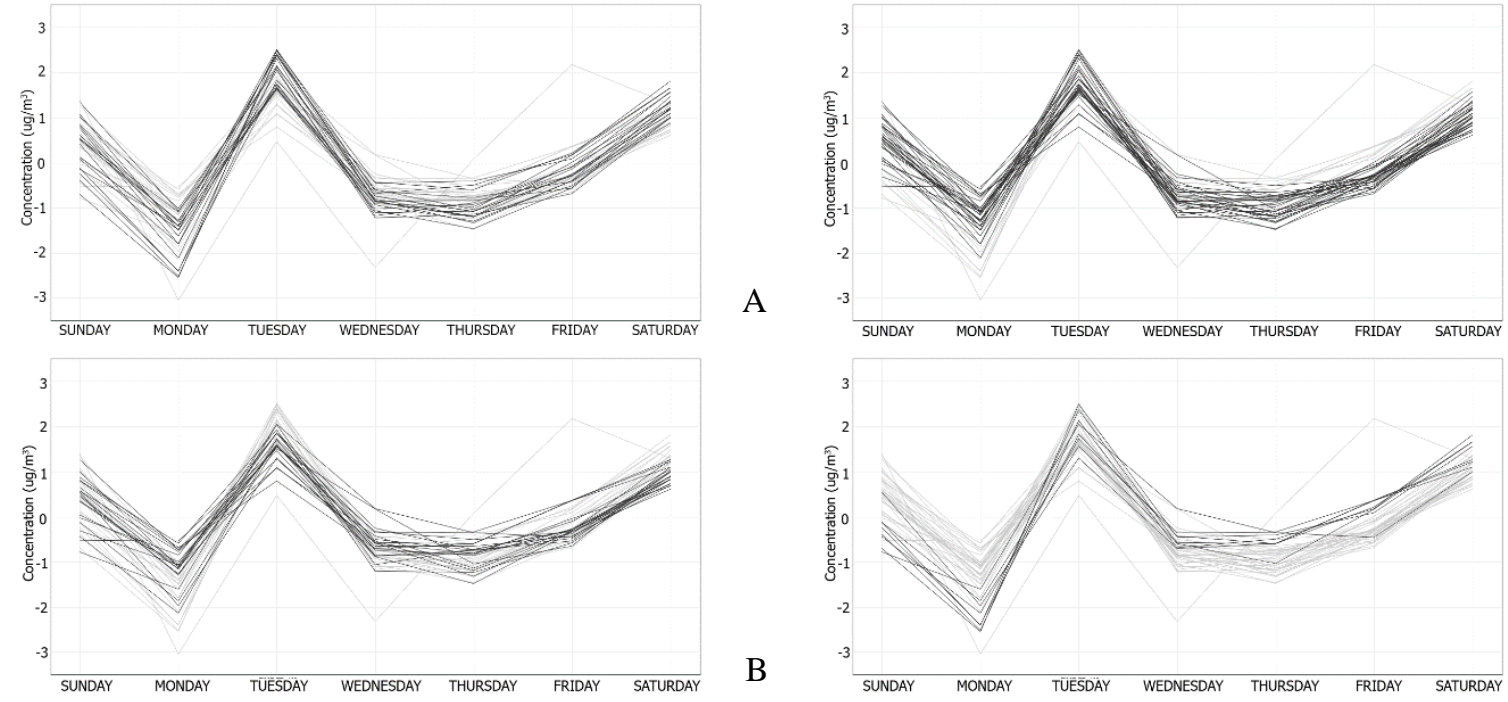

A

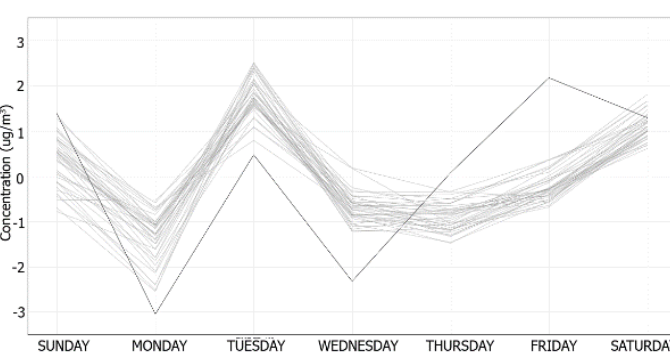

B
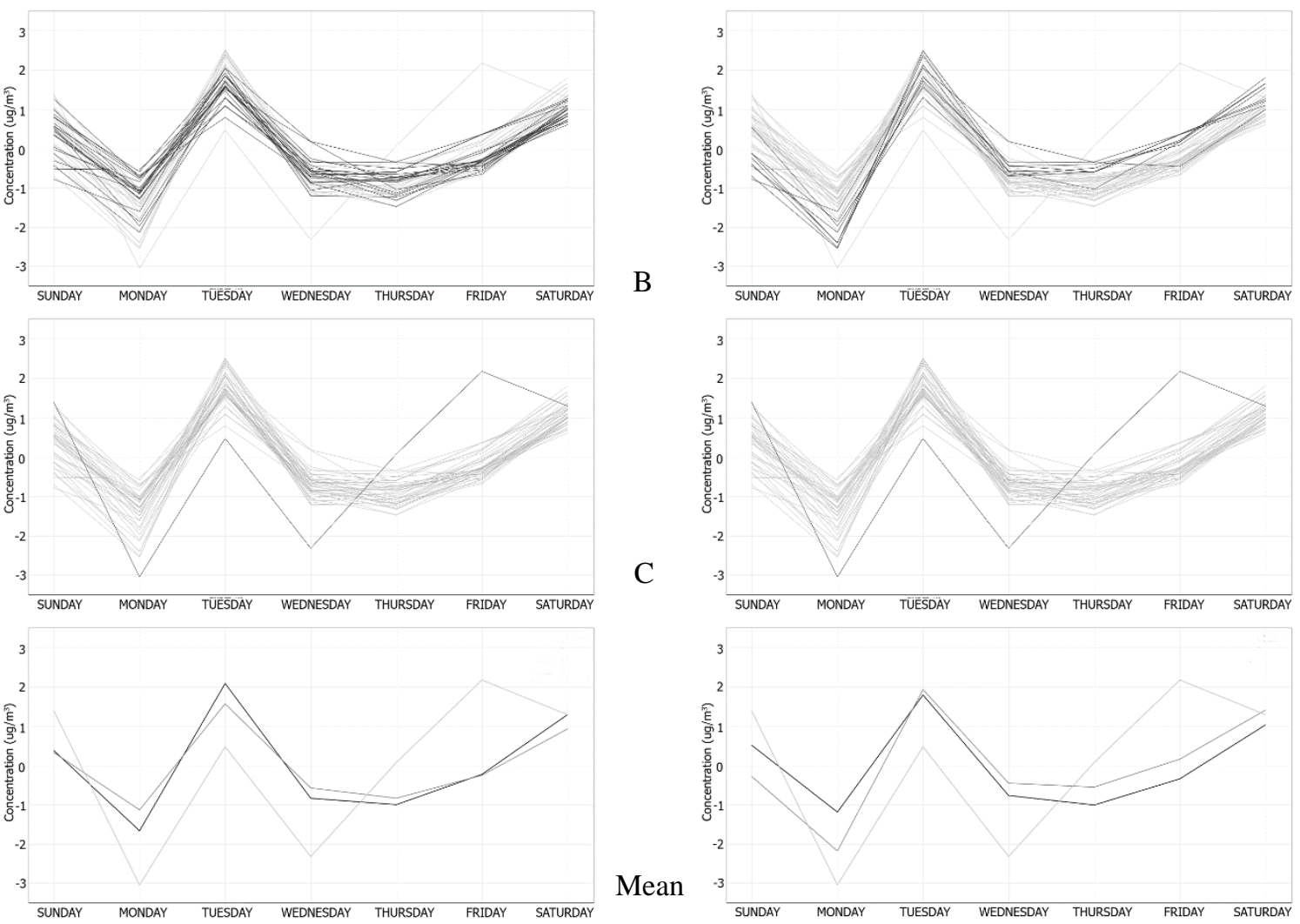

C
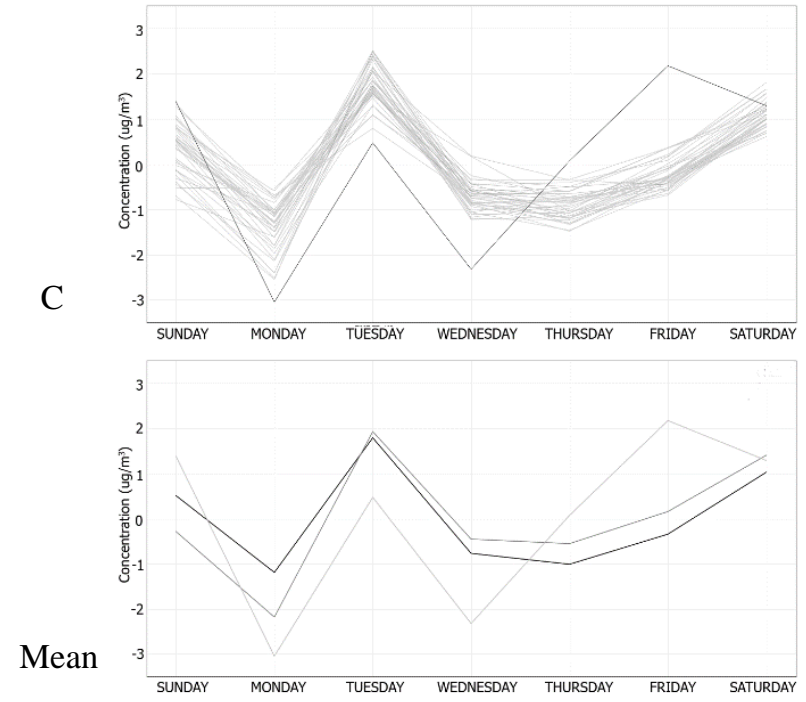

Figure 4 Weekly seasonal component of PM10. Left A-C, clustering from K-Means (DTW), Left D, mean of KMeans (DTW) clusters. Right A-C clustering from $K$-Shape, Right D, mean of K-Shape cluster. 

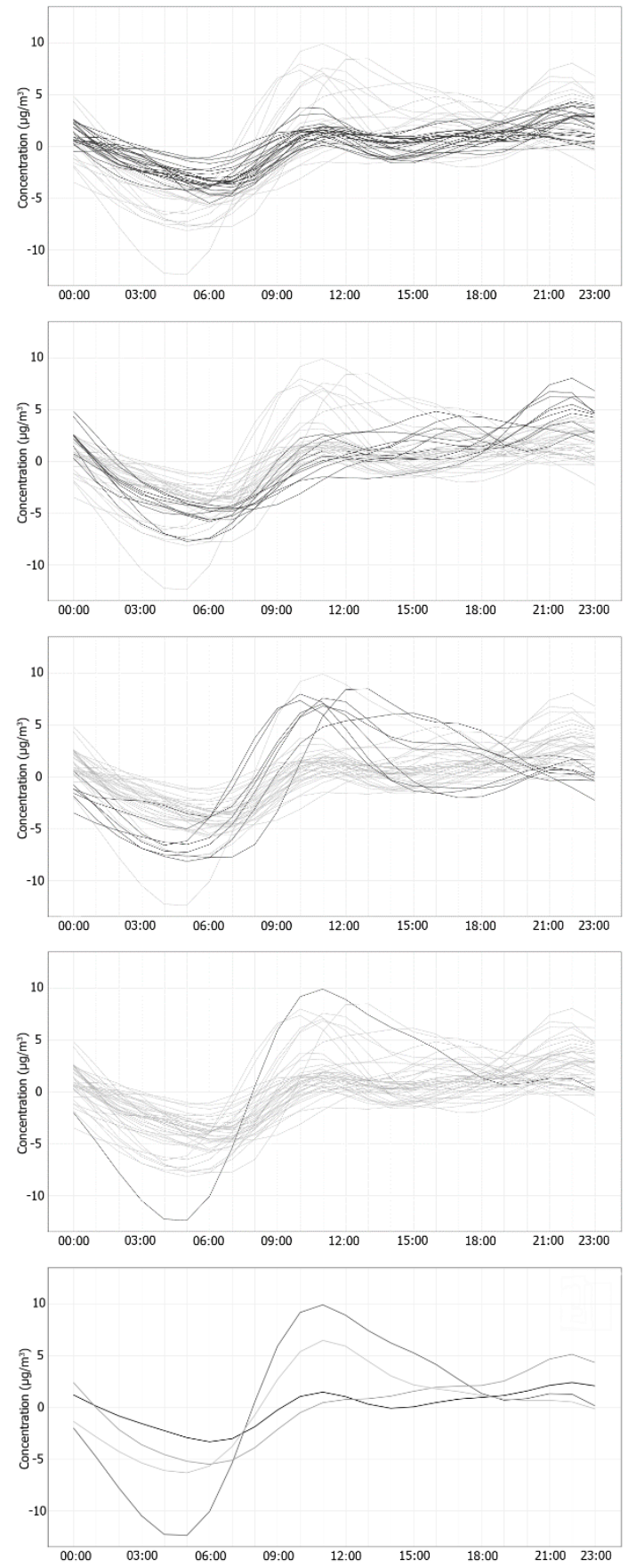

A

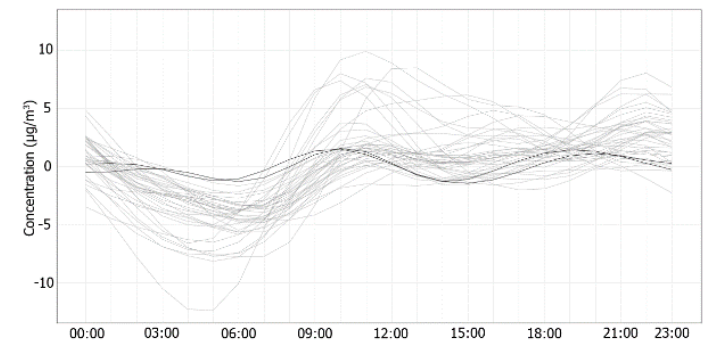

B

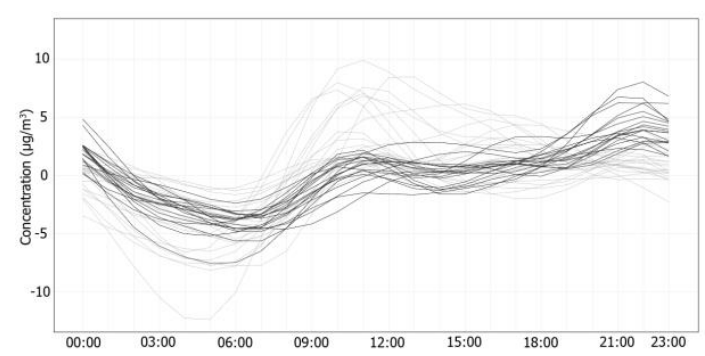

$\mathrm{C}$

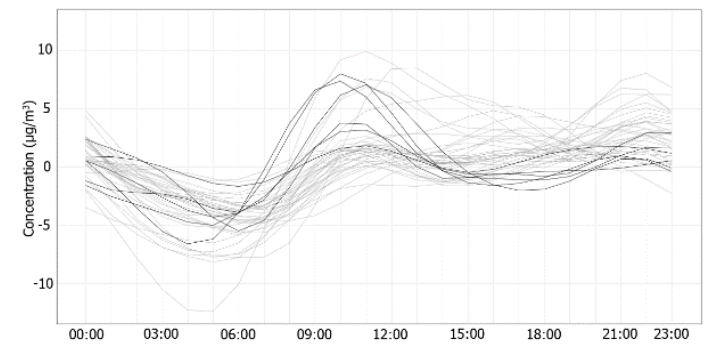

$\mathrm{D}$

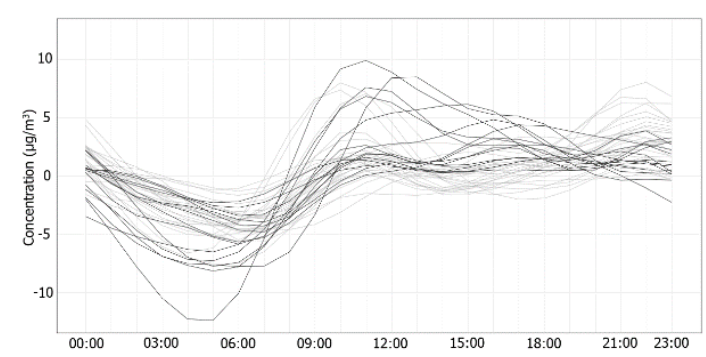

Mean

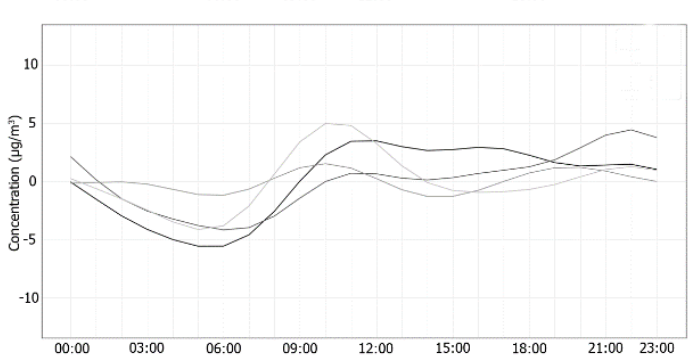

Figure 5 Daily seasonal component of PM10. Left A-C, clustering from K-Means (DTW), Left D, mean of KMeans (DTW) clusters. Right A-C clustering from K-Shape, Right D, mean of $K$-Shape cluster.

\section{Discussion}

For studied number of clusters, K-Shape has an average silhouette score of 0.68 and 0.61 vs. 0.61 and 0.55 for K-Means (for DTW and Euclidean distance metric respectively). Hence, while K-Shape performed slightly better as compared to K-Means, the results of two methodologies provide different (but equally important) insights into the variances in $\mathrm{PM}_{10}$ seasonal cycles.

\subsection{Annual Seasonal Component Cycle}

Annual cycle of all the AQMs indicates that winter (December - January) and spring (March - April - May) has the highest concentration of $\mathrm{PM}_{10}$. Cold air outbreak in southern china sea during winter and Asian dust storm (Kim and Park 2001) are two major causes for the peaks in annual cycles. For 
K-Means, AQM in cluster A have marginally lower values in winter and higher value in summer as compared to cluster B. Four AQMs in cluster $\mathrm{C}$ are characterized by more extreme values as compared to A \& B. On the other hand, for K-Shape, cluster A AQMs are characterized by more consistent change in pattern, as compared to cluster B. Cluster C only has one AQM, which has exceptionally high concentration in Jan - Feb but slightly lower concentration in fall (Sept - Nov), as compared to cluster A and B. These results are in contrast to (Bigi and Harrison 2010) study on London in which they found annual cycle for mean of all AQMs to have no clear pattern for $\mathrm{PM}_{10}$.

\subsection{Weekly Seasonal Component Cycle}

Among the three seasonal cycles, weekly cycle has very small impact on concentration levels. All but one AQM have a similar weekly cycle, with peaks observed during Tuesday and Saturday. K-Means based cluster A and B are predominantly same and are in fact put together if the number of clusters specified is two. On the other hand, AQMs in K-Shape cluster B has lower concentration for Monday, but higher concentration between Thursdays - Saturday as compared to cluster A. Cluster C has only one observation in both the cases due to its unique peak on Friday.

\subsection{Daily Seasonal Component Cycle}

As expected, a general trough in $\mathrm{PM}_{10}$ concentration is observed during nighttime (00:00 - 06:00) after which the concentration increases rapidly. From K-Means classifications, cluster $\mathrm{A}$ is characterized by relatively smaller slump during nighttime and stable or small increase in concentration after the morning peak. Cluster B has lower concentration in nighttime as compared to $\mathrm{A}$, which increases continuously till 22:00. Cluster $\mathrm{C}$ is characterized by very high morning peak and then declines continuously afterwards. Cluster D only has one AQM and shows the same features of cluster $\mathrm{C}$, except that the nighttime low and morning peaks are more extreme. In case of $\mathrm{K}$-Shape classification, cluster A show only small variation throughout the day. Cluster B and C are similar to that K-Means cluster, but are rather more tightly packed. Cluster D on the other hand shows considerably different patterns, indicating that increase in the number of clusters is required.

\section{Conclusion}

In this study, seasonal decomposition and clustering using K-Means (DTW) and K-Shape is applied to the $\mathrm{PM}_{10}$ concentration time series from 40 AQMs located within the administrative boundary of Seoul. Unlike (Yang, Ning et al. 2017) conclusion that the K-Shape produces superior clustering of building energy usage time series, this work show that both classifications provide a different understanding of patterns in $\mathrm{PM}_{10}$ concentrations. The results from this study will be utilized for developing land use regression model to investigate relationships between urban and traffic characteristics and pollution concentration. This would be based on the methodology utilized by (Kim and Guldmann 2015), however, instead of raw data used in the previous study, we expect utilization of only seasonal component would improve the model since such dependent variable would be free of long term trend and noises due to short term fluctuations.

\section{Appendix. Supplementary Information}

Raw data associated with this article can be found at airkorea's API (http://openapi.airkorea.or.kr/).

\section{References}

Ahmed, E., K.-H. Kim, Z.-H. Shon and S.-K. Song (2015). "Long-term trend of airborne particulate matter in Seoul, Korea from 2004 to 2013." Atmospheric Environment 101: 125-133.

Armstrong, J. S. and F. Collopy (1992). "Error measures for generalizing about forecasting methods: Empirical comparisons." International Journal of Forecasting 8(1): 69-80.

Berndt, D. J. and J. Clifford (1994). Using dynamic time warping to find patterns in time series. KDD workshop, Seattle, WA. 
Bigi, A. and R. M. Harrison (2010). "Analysis of the air pollution climate at a central urban background site." Atmospheric Environment 44(16): 2004-2012.

Harvey, A. C. and S. Peters (1990). "Estimation procedures for structural time series models." 9(2): 89-108.

Harvey, A. C. and N. Shephard (1993). Structural time series models. Handbook of Statistics, Elsevier. 11: 261-302.

Kampa, M. and E. Castanas (2008). "Human health effects of air pollution." Environmental Pollution 151(2): 362-367.

Kim, B.-G. and S.-U. Park (2001). "Transport and evolution of a winter-time Yellow sand observed in Korea." Atmospheric Environment 35(18): 3191-3201.

Kim, Y. and J.-M. Guldmann (2015). "Land-use regression panel models of NO2 concentrations in Seoul, Korea." Atmospheric Environment 107: 364-373.

Li, L., J. Qian, C.-Q. Ou, Y.-X. Zhou, C. Guo and Y. Guo (2014). "Spatial and temporal analysis of Air Pollution Index and its timescale-dependent relationship with meteorological factors in Guangzhou, China, 2001-2011." Environmental Pollution 190: 75-81.

McZgee, V. E. and W. T. Carleton (1970). "Piecewise Regression." Journal of the American Statistical Association 65(331): 1109-1124.

ME (2013). 2nd seoul metropolitan air quality improvement plan (2015 -2024), Ministry of Environment.

Montero, P. and J. A. Vilar (2014). "TSclust: An R Package for Time Series Clustering." 2014 62(1): $43 \%$ J Journal of Statistical Software.

Paparrizos, J. and L. Gravano (2015). k-Shape: Efficient and Accurate Clustering of Time Series. Proceedings of the 2015 ACM SIGMOD International Conference on Management of Data. Melbourne, Victoria, Australia, ACM: 1855-1870.

Rousseeuw, P. J. (1987). "Silhouettes: A graphical aid to the interpretation and validation of cluster analysis." Journal of Computational and Applied Mathematics 20: 53-65.

Stern, A. C. (1977). Air Pollution: The effects of air pollution, Elsevier.

Tavenard, R. (2017). tslearn: A machine learning toolkit dedicated to time-series data.

Taylor, S. J. and B. Letham (2018). "Forecasting at Scale." The American Statistician 72(1): 37-45.

Tibshirani, R., G. Walther and T. Hastie (2001). "Estimating the number of clusters in a data set via the gap statistic." 63(2): 411-423.

Yang, J., C. Ning, C. Deb, F. Zhang, D. Cheong, S. E. Lee, C. Sekhar and K. W. Tham (2017). "kShape clustering algorithm for building energy usage patterns analysis and forecasting model accuracy improvement." Energy and Buildings 146: 27-37.

Zhang, X. Y., S. L. Gong, T. L. Zhao, R. Arimoto, Y. Q. Wang and Z. J. Zhou (2003). "Sources of Asian dust and role of climate change versus desertification in Asian dust emission." Geophysical Research Letters 30(24). 